\title{
O conceito de número na proposta curricular de matemática do Estado de Santa Catarina: uma análise a luz da abordagem histórico - cultural
}

\author{
Josélia Euzébio da Rosa \\ Doutoranda em Educação - Educação Matemática \\ UFPR- Universidade Federal do Paraná \\ Joselia.euzebio@yahoo.com.br \\ Ademir Donizeti Caldeira \\ UFSC - Universidade Federal de Santa Catarina \\ miro@ced.ufsc.br \\ Ademir Damazio \\ UNESC - Universidade do Extremo Sul Catarinense \\ ademir@unesc.net
}

Resumo: a proposta Curricular de matemática do Estado de Santa Catarina constitui o objeto de estudo do presente artigo. A referida proposta, que se diz fundamentada na abordagem Histórico-Cultural (AHC), foi elaborada por um grupo de professores da educação básica da rede estadual de ensino. Nosso objetivo foi investigar os possíveis pontos de convergências e divergências entre as orientações para o desenvolvimento dos conceitos matemáticos apresentadas na Proposta e o desenvolvimento de conceitos na abordagem histórico-cultural. Mas especificamente em Vigotski e Davídov. Nas análises, priorizamos um conceito que a criança inicia seu conhecimento quando entra na escola e que conserva a sua entidade durante todo o processo de estudo da matemática escolar: o conceito de número e sua significação aritmética, geométrica e algébrica. Ao analisar a proposta, percebemos que as orientações apresentadas para o desenvolvimento do conceito de número, estão mais próximas ao desenvolvimento histórico desse objeto matemático e aos índices de livros didáticos do que ao desenvolvimento dos conceitos em Vigotski e Davidov. O movimento do desenvolvimento do conceito de número na evolução histórica e na proposta curricular segue do particular para o geral. Porém, a ordem genética do desenvolvimento dos conceitos, de acordo com a AHC, na idade escolar, consiste no inverso, do geral para o particular, um conceito se sobrepõe aos outros e incorpora o mais particular.

Palavras - Chave: conceito de número, abordagem histórico-cultural, Proposta Curricular do Estado de Santa Catarina. 


\section{Intodução}

A produção e implementação da Proposta Curricular de Matemática do Estado de Santa Catarina (PC/SC) é apresentada como sendo fundamentada na Abordagem HistóricoCultural (AHC). A elaboração do currículo catarinense foi coordenada pela Secretaria Estadual da Educação, envolveu um grupo de professores que atua na educação básica da rede pública estadual e contou com consultores pesquisadores em Educação Matemática. Desse processo, iniciado em 1988, resultou na produção de duas versões (1991 e 1998) e vários outros documentos complementares subsidiadores da prática pedagógica daqueles professores que têm na PC/SC a referência da ação docente. Todos os documentos são fundamentados na versão de 1998.

Ao comungarmos com o mesmo referencial temos percebido, em nossos estudos, alguns aspectos teóricos da Proposta em foco que merecem serem refletidos. Assim, o objetivo do presente artigo é fazermos uma discussão sobre os possíveis pontos de convergências e divergências entre as orientações para o desenvolvimento do conceito de número apresentado na $\mathrm{PC} / \mathrm{SC}$ e os pressupostos teóricos da $\mathrm{AHC}$, especificamente em alguns trabalhos de Vigotski ${ }^{1}$ e Davydov ${ }^{1}$.

De acordo com a PC/SC, o conceito de número é elaborado sistematicamente desde quando a criança entra na escola e se estende durante todo o processo de estudo da matemática escolar. Dos vários aspectos abordados na PC/SC, nossas análises priorizam: o "quadro de ênfase dos conteúdos" e as "orientações pedagógicas". Acreditamos que são nesses dois aspectos que estão as maiores possibilidades do Grupo responsável pela elaboração manifestar coerências ou incoerências, entre os pressupostos teóricos e as orientações pedagógicas.

\section{O desenvolvimento de conceitos na abordagem histórico-cultural}

Dentro de um processo geral, Vygotsky (1994, p. 61) distingue duas linhas qualitativamente diferentes do desenvolvimento humano, quanto à sua origem: "de um lado, os processos elementares, que são de origem biológica; de outro, as funções psicológicas superiores, de ordem sócio-cultural”. Segundo Lúria (1988b, p. 36), Vigotski acredita que as funções psicológicas superiores dos seres humanos "sugiram através da intrincada interação de fatores biológicos que são parte de nossa constituição como homo sapiens e de fatores culturais que evoluíram ao longo de dezenas de milhares de anos da história humana".

\footnotetext{
${ }^{1} \mathrm{Na}$ tradução para o português e espanhol existem várias grafias, iremos conservar a grafia de cada referência. 
Por isso, Vygotsky (1991) considera a aprendizagem um momento necessário para que se desenvolvam essas características humanas não naturais, mas formadas historicamente. Não há paralelismo entre aprendizagem e desenvolvimento, o ritmo da aprendizagem não coincide com o ritmo do desenvolvimento. Vigotski considera o maior dos equívocos supor que as leis externas da estruturação do processo letivo coincidem "inteiramente com as leis internas de estruturação dos processos de desenvolvimento desencadeados pela aprendizagem" (2000, p. 322).

O processo geral de formação de conceitos é constituído ontogeneticamente, segundo Vigotski (2000), por três estágios: o sincrético, o complexo e o conceito propriamente dito. No primeiro, o sincrético, a criança desenvolve a aritmética natural baseada na percepção direta de quantidades, por comparações.

Lúria, com base nos estudos de Vigotski, estudou o processo pelo qual a criança desenvolve as habilidades para contar e registrou algumas técnicas empregadas na divisão. Neste estágio, o referido autor diz que as crianças tentam "dividir diretamente a pilha de blocos ou fichas, sem o uso de qualquer técnica auxiliar. Elas reuniam as peças sobre a mesa e, em seguida, as distribuíam 'a olho', com suas mãos, empurrando algumas a cada um de seus colegas" (1988a, p. 96, destaque do autor). O resultado da divisão "é impreciso e totalmente dependente daquilo que a criança abarca em seu campo de visão" (idem). Esta é uma fase inicial no desenvolvimento infantil, pela qual se defende a necessidade da percepção direta das formas numéricas na idade escolar, com a utilização de objetos, como: palitos, cubos, etc. (Vygotski, 1995).

O segundo estágio do desenvolvimento dos conceitos, denominado como pensamento complexo, acontece o progresso da percepção direta de quantidade para a percepção mediada. Nesta fase, denominada por Vygotski de aritmética mediada, a criança começa a comparar quantidades com determinados signos e a operar com tais signos.

O terceiro e último estágio do desenvolvimento de conceitos, considerado por Vigotski (2000) como conceito propriamente dito, a criança desenvolve a aritmética cultural. Segundo Vygotski (1995), a criança tem mais facilidade em operar com figuras numéricas devido ao estreito vínculo entre quantidade e percepção da forma, porém, isso não faz parte da aritmética cultural. A criança deve libertar-se das formas concretas e passar ao cálculo mediado.

De acordo com Vygotski (1996), é com a formação de conceitos que todo o conteúdo do pensamento se renova e se reestrutura, o que era, a princípio, exterior (concepção de mundo, interesses...) passa a ser interior. Para o autor, é o pensamento em conceitos, formados 
na fase de transição, que abre diante do adolescente o mundo da consciência social objetiva e o mundo da ideologia social. É o momento em que o adolescente entra em uma via de desenvolvimento que lhe conduzirá ao domínio da última etapa e superior de desenvolvimento: o pensamento dialético.

Ainda em relação ao desenvolvimento de conceitos, Vigotski (2000) faz uma análise das relações dos conceitos espontâneos e científicos. Segundo o autor, os conceitos espontâneos fazem com que o indivíduo realize uma leitura do objeto em si e forme a consciência do próprio objeto nele representado. Entretanto, não tem consciência do ato de pensamento por meio do qual concebe esse objeto, como também do próprio conceito.

O desenvolvimento dos conceitos científicos começa, ao longo da idade escolar, pelo trabalho com o próprio conceito, pela definição verbal e operações que pressupõe até operações não espontâneas. O desenvolvimento dos conceitos científicos começa no que ainda não foi plenamente desenvolvido nos espontâneos.

Segundo Vigotski (2000) um novo conceito, uma nova generalização surge com base no conceito ou generalização anterior. A generalização das operações e do pensamento é nova e superior à generalização das propriedades numéricas dos objetos no conceito aritmético. Por trás do conceito aritmético do aluno não há nada, é um estágio conclusivo onde o movimento está vinculado apenas às condições da situação aritmética. Já por trás dos conceitos algébricos estão os conceitos aritméticos como caso particular de um conceito mais geral, o que possibilita ao adolescente colocar-se acima da situação. A operação com os conceitos algébricos proporciona maior liberdade "por partir da fórmula geral por força da qual ela é independente de uma expressão aritmética determinada" (VIGOTSKI, 2000, p. 372).

Davydov (1998), um dos seguidores de Vigotski, tem como objetivo, criar uma educação que desenvolva os alunos em sua amplitude física, moral e intelectual. Para ele, a educação escolar não pode se limitar apenas à transmissão de conhecimentos, mas, entre outros aspectos, deve ensinar os alunos a encontrar seus próprios caminhos para formação científica.

Para Davydov (1982), a coluna vertebral da disciplina é o programa, concebido como descrição sistemática do conhecimento a ser assimilado. É do programa de conteúdos que se estabelecem os métodos de ensino, o material didático, os prazos de estudo e outros elementos do processo docente. Para elaborar os programas de ensino, o referido autor diz que é necessário ir além do conteúdo da ciência correspondente. É imprescindível que se tenha por base, a idéia lógica e precisa sobre a estrutura das ciências como forma peculiar do reflexo da 
realidade. Além disso, não menos importante é o entendimento do nível de desenvolvimento de natureza psicológica da conexão existente entre a atividade mental dos alunos e o conteúdo dos conhecimentos a serem assimilados, bem como o domínio dos métodos formativos dessa atividade.

Davydov (1982) apresenta as particularidades do pensamento empírico e do pensamento teórico. O pensamento teórico opera mediante conceitos científicos. Seu objeto é a integridade, a unidade do diverso é o sistema. O processo direcionador que expressa a natureza do pensamento teórico é o da ascensão do abstrato ao concreto. No pensamento empírico existem objetos singulares concretos fora do homem e de seu pensamento. Esse pensamento opera mediante a identificação dos objetos sensoriais concretos e a comparação dos dados sensoriais concretos. A educação escolar deve se empenhar em desenvolver os fundamentos do pensamento teórico dos alunos, o que daria outra dimensão para pensamento empírico.

Também são apresentados por Davídov (1987), quatro princípios didáticos fundamentais que predominam educação escolar atual. Em oposição a estes, sugere novos princípios para garantir, nos alunos, a formação de um pensamento teórico autônomo, conforme segue:

1 - Caráter sucessivo x caráter novo do conhecimento: De acordo com o princípio do caráter sucessivo, a escola tradicional ${ }^{2}$ conserva a ligação dos conhecimentos cotidianos que a criança recebe antes de ingressar na escola com os conhecimentos das séries iniciais. Porém, para Davídov, com o ingresso nas séries iniciais a criança deve sentir claramente o caráter novo e a peculiaridade dos conceitos que agora recebe. Deve perceber que se trata de conceitos científicos e que devem ser tratados com um procedimento distinto em comparação aos conhecimentos cotidianos adquiridos no período pré-escolar.

2 - Acessibilidade $\mathbf{x}$ educação que desenvolve: É com base no princípio da acessibilidade que se ensina aos alunos apenas àquilo que são capazes de assimilar de acordo com sua idadecapacidade. O ensino utiliza unicamente as possibilidades já formadas e presentes nos alunos. Segundo Davídov, o princípio da acessibilidade deve ser transformado no princípio da educação que desenvolve, que dirige os ritmos e o conteúdo do desenvolvimento por meio de

\footnotetext{
${ }^{2}$ Com o termo tradicional Davídov designa um sistema relativamente único de educação européia, da qual nosso país recebeu e forte influência.
} 
ações que exercem influência sobre este. Ou seja, o ensino deve levar consigo o desenvolvimento.

3 - Caráter consciente $\mathbf{x}$ princípio da atividade: De acordo com o princípio do caráter consciente, todo o conhecimento se apresenta em forma de abstrações verbais claras e cada abstração verbal deve ser correlacionada pela criança com uma imagem sensorial completamente definida e precisa. Em oposição ao princípio do caráter consciente, Davídov (1987) sugere o princípio da atividade como fonte, meio e forma de estruturação, conservação e utilização dos conhecimentos.

4 - Caráter visual, direto ou intuitivo x caráter objetal: A orientação para o Princípio do caráter visual, direto ou intuitivo é resultado da posição da escola tradicional, que com todo o seu conteúdo e todos os seus métodos de ensino projeta exclusivamente a formação, nas crianças, do pensamento empírico. Em oposição ao princípio do caráter visual direto ou intuitivo, que dita a passagem do particular para o geral, Davídov sugere o princípio do caráter objetal, que se atém na possibilidade de os alunos descobrirem o conteúdo geral de um certo conceito como base para a ulterior identificação de suas manifestações particulares.

\section{A proposta curricular de Santa Catarina e a abordagem histórico-cultural}

Em relação à formação de conceitos, a $\mathrm{PC} / \mathrm{SC}^{3}$ afirma que a função da escola é socializar os conhecimentos científicos produzidos historicamente, o que também é defendido pela AHC. Entretanto, as orientações metodológicas e a proposta de sequiência dos conceitos, contrariam o que defende Vigotski (relação entre conceitos científicos e espontâneos) e Davydov (relação entre pensamento teórico e o pensamento empírico), pois a PC/SC indica que o ponto de partida deve ser os conceitos cotidianos. Mesmo sendo um documento destinado à Educação Básica, as questões teóricas abordadas, até certo ponto de forma tangencial, estão relacionadas apenas à educação infantil.

Embora não esteja explícito, a orientação pedagógica da PC/SC em relação ao cálculo segue o decurso do desenvolvimento das funções psicológicas superiores apresentado por Vigotski. A proposição é que se inicie pelo cálculo oral das operações aritméticas e, a partir daí, o desenvolvimento dos procedimentos algoritmos escritos de forma sistematizada; primeiro como função interpsíquica, no social, com a presença do interlocutor e do aspecto 
sonoro da fala. Depois, como funções intrapsíquicas, o algoritmo escrito, concomitantemente com apropriação das significações conceituais.

Também, sem um tratamento mais aprofundado, outro aspecto de convergência entre PC/SC e AHC é a idéia de sistema conceitual indicada nas "orientações pedagógicas" para os números fracionários. A sugestão é de que as diversas formas de representações desses números sejam apresentadas aos alunos. Porém, vale dizer que a referência se limitada apenas ao conceito de número fracionário em si, não levando em consideração a relação entre os outros conceitos, a ponto de dicotomizar expressão algébrica e pensamento algébrico.

Segundo a PC/SC deve-se minimizar o desenvolvimento de habilidades técnicas de manipulação de expressões algébricas e maximizar o desenvolvimento do pensamento algébrico. A nosso ver, tais habilidades devem ser expressão do pensamento algébrico desenvolvido. Subjacente a essa sugestão, a ênfase incide na concepção empírica do pensamento algébrico em oposição a AHC que prioriza a essência abstrata da matemática no processo de ensino-aprendizagem.

Para a PC/SC a essência abstrata da matemática dificulta para o aluno o acesso ao saber, por isso, deve-se partir do conhecimento que o aluno já possui e gradativamente ampliá-lo. As orientações apresentadas para o desenvolvimento do conceito de número, por exemplo, estão muito mais próximas ao desenvolvimento histórico desse objeto matemático e aos índices de livros didáticos do que ao desenvolvimento dos conceitos em Vigotski, com uma única exceção em relação à seqüência histórica, que consiste, segundo Caraça (1984) na seguinte ordem: números naturais - números racionais - números irracionais e reais - números relativos. Na evolução histórica, os números relativos foram os últimos a serem criados no campo que conhecemos hoje como reais. No entanto, a seqüência sugerida na PC/SC é: números naturais - números racionais - números inteiros - números irracionais e reais. Vale dizer que essa seqüência não é exclusividade do currículo catarinense, é uma orientação da maioria dos livros didáticos de matemática.

O movimento do desenvolvimento do conceito de número na evolução histórica e na PC/SC segue do particular para o geral. Porém, a ordem genética do desenvolvimento dos conceitos em Vigotski, na idade escolar, consiste no inverso, de "cima para baixo, do geral para o particular e do topo da pirâmide para base" (2000, p. 165).

\footnotetext{
${ }^{3}$ Vale lembrar que a PC/SC em referência é a versão de 1998.
} 
Um conceito se sobrepõe aos outros e incorpora o mais particular. Isso implica, como propõe Davidov, em começar, na escola, pelos números reais e não pelos números naturais.

Em relação à idéia de número natural, Caraça diz que "não é um produto puro do pensamento, independe da experiência; os homens não adquiriram primeiro os números para depois contarem; pelo contrário, os números naturais foram se formando lentamente pela prática diária de contagens" (1984, p. 04).

Os números racionais, por sua vez, surgiram da necessidade prática da medida. Medir consiste em "comparar duas grandezas da mesma espécie - dois comprimentos, dois pesos, dois volumes, etc" (CARAÇA, 1984, p. 29). Do ponto de vista aritmético os racionais surgiram da impossibilidade da divisão, quando o dividendo não é múltiplo do divisor (CARAÇA, 1984).

Medir e contar, segundo Caraça (1984, p. 29), "são operações cuja realização a vida de todos os dias exige com maior frequiência". Da realidade prática por meio da medida e da contagem a humanidade tirou a idéia dos números naturais e racionais, depois tirou todas as consequiências dessa idéia: os irracionais, para resolver o problema teórico da medida e, por último, os números relativos para resolver o problema das grandezas que podem ser tomadas em dois sentidos opostos, concluindo o campo relativo tradicionalmente conhecido como o campo dos reais. Ou seja, "é o número natural, surgindo da necessidade da contagem; o número racional, da medida; o número real, para assegurar a compatibilidade lógica de aquisições diferentes" (idem, p. 125).

\section{Para Giardinetto:}

...o homem inicialmente elabora seu conhecimento a partir da realidade em sua volta gerando um conjunto de dados empíricos. Posteriormente, esses dados empíricos lançam as bases para progressivos esforços sistematizadores, determinando uma nova etapa em que a produção do conhecimento passa a se processar em esferas de abstrações sobre novas abstrações, em outras palavras, a teoria ganha autonomia frente à prática, sua inspiradora (1997, p. 48).

O número natural e o racional são abstrações elaboradas historicamente a partir do objeto; o número real revela uma abstração em si traduzindo-se, pois, no conceito propriamente dito. É no conceito (números reais) que todas as operações fundamentais do cálculo são possíveis de serem realizadas. Entretanto, é importante salientar que o "conceito, 
segundo a lógica dialética, não inclui unicamente o geral, mas também o singular e o particular" (VYGOTSKI, 1996, p. 78).

As propriedades formais das sete ${ }^{4}$ operações matemáticas constituem o conjunto das leis operatórias do cálculo. As leis operatórias e suas propriedades são mantidas em todos os campos numéricos, porém, quanto mais particular eles forem, diminui as possibilidades de atribuição de significados. No campo natural, por exemplo, "todas as operações inversas ${ }^{5}$ apresentam casos de impossibilidade, por vezes mais freqüentes que os de possibilidade" (CARAÇA, 1984, 28).

Se as propriedades formais das operações fundamentais formam, como vimos acima, o conjunto das leis operatórias do cálculo, então não faz sentido ficar nos primeiros anos do ensino escolar em campos numéricos onde a maioria das operações fundamentais não é possível de ser realizada. Isso significa negar à criança o conhecimento de número em sua totalidade, isto é recusar a base do cálculo, pois os fragmentos das propriedades formais das operações possíveis nos campos numéricos mais particulares não permitem a liberdade do cálculo para o pensamento da criança.

Iniciar o ensino com atenção somente ao campo dos naturais, como sugere a $\mathrm{PC} / \mathrm{SC}$, significa orientá-lo por uma etapa de desenvolvimento já realizada, tornando-o ineficaz sob o ponto de vista do desenvolvimento geral da criança. Isso ocorre porque o ensino, assim orientado, vai atrás do processo de desenvolvimento ao invés de orientá-lo. Na escola, a criança deve aprender o novo, o que ainda não sabe e pode lhe ser acessível por meio da colaboração. Davydov (1982) aponta que o ensino escolar deve proporcionar às crianças conceitos genuinamente científicos, desenvolver neles o pensamento científico e as capacidades para o sucessivo domínio independente do número sempre ascendente de novos conhecimentos científicos.

Como diz Vygotski, quando a criança chega à escola já tem elaborado e desenvolvido, por meio de atividades espontâneas, um amplo tecido do conceito de número. Cabe à escola começar no que ainda não foi plenamente desenvolvido nos conceitos espontâneos, em seu aspecto mais geral, que são os números reais. O conceito de número real vai se desenvolver de cima para baixo por meio dos números naturais e racionais que foram elaborados na atividade espontânea da contagem e de medida. Esses, por sua vez, irão percorrer o caminho contrário

\footnotetext{
${ }^{4}$ As sete operações fundamentais são: adição, subtração, multiplicação, divisão, radiciação, logaritmação, e potenciação.

5 As operações inversas são: subtração, como inversa da adição; divisão como inversa da multiplicação; a radiciação e a logaritmação como inversa da potenciação.
} 
de baixo para cima por meio dos números reais, caracterizando assim, a zona de desenvolvimento imediato.

Do exposto pode-se inferir que é só nos números reais, tomados em sua dinâmica, atividade e movimento, que o conceito de número reflete sua verdadeira natureza. A relação do número real com o objeto pressupõe a existência de relação entre os naturais, racionais, irracionais e inteiros, ou seja, um sistema de conceitos. Segundo Vigotski, cada conceito deve ser tomado em conjunto da mesma forma que uma "célula deve ser tomada com todas as suas ramificações através das quais ela se entrelaça com o tecido comum" (2000, p. 294).

Em um determinado momento do desenvolvimento histórico da matemática, quando humanidade só havia desenvolvido os números naturais, seria aceitável desprender de algum tempo do trabalho escolar para o ensino-aprendizagem dos mesmos. Mas, hoje, o conceito de número, não só foi ampliado e recebeu maior precisão, como também foi renovado como um sistema integral. Como diz Davydov (1982), o conteúdo de uma disciplina não é idêntico à totalidade dos avanços da ciência correspondente, mas é obrigação da educação proporcionar as abstrações e generalizações ao nível inteiramente moderno que escreve a lógica dialética.

Portanto, diante desses pressupostos da AHC, inferimos como equivocada teoricamente a indicação da $\mathrm{PC} / \mathrm{SC}$ que o ponto de partida seria o ensino dos números naturais, em detrimento ao conceito teórico de número real. Contudo, não queremos dizer que de início seja apresentada às crianças a definição formal de número real. Isso, segundo Vygotski (2000), teria como consequiência um simples verbalismo sem significado e sem sentido. A preocupação é com atividades que levem o aluno elaboração conceitual e ao desenvolvimento do pensamento teórico.

\section{REFERÊNCIAS}

CARAÇA, Bento de Jesus. Conceitos fundamentais da Matemática. Lisboa: Livraria Sá da Costa editora, 1984. 318p.

DAVÍDOV, V. V. Análisis de los principios didácticos de la escuela tradicional y posibles principios de enseñanza en el futuro próximo. In: La psicología Evolutiva y pedagógica en la URSS. Moscú, Progresso. 1987 p. 143-155.

DAVYDOV, V. V. La Renovación de la educación y el desarrollo mental de los alumnos. Revista de Pedagogia. Santiago, año XLVIII, N 403. 197-199, jun, 1998.

DAVYDOV, V. V. Tipos de generalización en la enseñanza. 1 ed. $2^{\mathrm{a}}$ reimpresión. Habana: 
Pueblo y Educación, 1982. 485p.

GIARDINETTO, J. R. B. O fenômeno da supervalorização do conhecimento cotidiano em algumas pesquisas da educação matemática. 1997. Tese (doutorado em educação) UFSCAR, São Carlos.

LÚRIA, A. R. A psicologia Experimental e o desenvolvimento infantil. In: VIGOTISKII, L. $\mathrm{S}$; et al. Linguagem, Desenvolvimento e Aprendizagem. São Paulo: Editora da Universidade de São Paulo, 1988a. p. 85-102.

LÚRIA, A. R. Vigotskii. In: VIGOTISKII, L. S; et al. Linguagem, Desenvolvimento e Aprendizagem. São Paulo: Editora da Universidade de São Paulo, 1988b. p. 21-38.

PC/SC, Secretaria de Estado da Educação (Santa Catarina). Proposta Curricular: uma contribuição para a escola pública do pré-escolar, $1^{\circ}$ grau, $2^{\circ}$ grau e educação de adultos. Florianópolis: IOESC, 1991.

PC/SC, Secretaria de Estado da Educação e do Desporto. Proposta Curricular de Santa Catarina. Florianópolis: GOGEM, 1998.

VIGOTSKI, L. S. A construção do pensamento e da linguagem. Trad. Paulo Bezerra. São Paulo: Martins Fontes, 2000. 496p.

VYGOTSKI, L. S. Obras Escogidas IV: Incluye Paidología del adolescente problemas de la psicología infantil). Madrid: Visor Distribuciones, 1996.

VYGOTSKI, L. S. Obras escogidas, III: Incluye Problemas del Desarrollo de la Psique. Madrid: Visor Distribuciones, 1995.

VYGOTSKY, L. S. A Formação social da mente. Trad. Neto J. C. et all. $5^{\text {a }}$ ed. São Paulo: Martins Fontes, 1994. 191p.

VYGOTSKY, L. S. Aprendizagem e desenvolvimento intelectual na idade escolar. In: LURIA, A. R; et al . Psicologia e Pedagogia: bases psicológicas da aprendizagem e do desenvolvimento. São Paulo: Editora Moraes ltda, 1991. p. 1-18. 